\title{
Toxicity and Antifeedant Activity of Selected Plant Extracts Against Lar- val Obliquebanded Leafroller, Choristoneura rosaceana (Harris)
}

\author{
Ayhan Gökçe ${ }^{1}$, Lukasz L. Stelinski*,2 ${ }^{\text {, Mark E. Whalon }}{ }^{3}$ and Larry J. Gut ${ }^{3}$ \\ ${ }^{\text {I} D e p a r t m e n t ~ o f ~ P l a n t ~ P r o t e c t i o n, ~ A g r i c u l t u r e ~ F a c u l t y, ~ G a z i o s m a n p a s ̧ a ~ U n i v e r s i t y, ~ T a s ̧ l ı c ̧ i f t l i k ~ Y e r l e s ̧ k e s i, ~ T o k a t, ~ T u r k e y ~}$ \\ ${ }^{2}$ Entomology and Nematology Department, Citrus Research and Education Center, University of Florida, Lake Alfred \\ FL, USA \\ ${ }^{3}$ Department of Entomology, Michigan State University, East Lansing, MI, USA
}

\begin{abstract}
Several plant extracts were evaluated against obliquebanded leafroller larvae to determine potential toxicity and antifeedant effects. Two of the plant extracts exhibited contact toxicity; the $\mathrm{LC}_{50}$ value of Humulus lupulus extract against $3^{\text {rd }}$ instar larvae was $24.5 \mu \mathrm{g} /$ insect. In a no choice context, larval survivorship was reduced $23-57 \%$ after feeding on a meridic pinto bean diet treated with the extracts. Furthermore, average female and male pupal weight was reduced for leafrollers that fed on diet treated with each of the individually-tested extracts at a $4 \%$ concentration (w/w). Incorporation of Bifora radians and $H$. lupulus into diet deterred larval feeding at a $1 \%$ concentration by weight. H. lupulus and Arctium lappa extracts were deleterious to larvae in each of the bioassay methods conducted, exhibiting toxic, developmental, and antifeedant effects. These two extracts may be promising candidates for further development as botanical insecticides that could potentially substitute broad-spectrum synthetic neurotoxins for leafroller control.
\end{abstract}

\section{INTRODUCTION}

The Obliquebanded leafroller, Choristoneura rosaceana (Harris), is a tortricid moth with a wide host range including woody plants in the Rosaceae as well as Ulmus, Populus, Quercus, Betula, and Tilia [1]. Depending on the geographic region and climate, there are one or two generations of adults per year with an overwintering second or third-instar larval generation [2]. The polyphagous larvae are primarily foliage feeders, but are also known to feed on and damage apple fruit [3].

Obliquebanded leafrollers are major pests in apple growing regions throughout the U.S.A. and Canada [4]. Due to azinphos-methyl resistance, population densities of this pest have increased in commercial apple growing regions in the Eastern United States [5]. Resistance to organophophates is also becoming prevalent in Canada $[6,7]$. Physiological resistance to other broad-spectrum insecticides and newer chemistries such as insect growth regulators has been also identified for several compounds including chlorpyrifos, esfenvalerate, and tebufenozide [4, 8].

Botanical insecticides such as azadirachtin are often effective alternatives to organophosphates or other neurotoxins for pest control due to multiple modes of action. These include toxicity, antifeedant and anti-oviposition effects $[9,10]$. Natural products containing secondary plant compounds such as terpenes, steroids, alkaloids, phenolics and cardiac glycosides [11] affect insect behavior and are toxic in some cases [12-18]. Identification of plant extracts that exhibit the

*Address correspondence to this author at the Entomology and Nematology Department, Citrus Research and Education Center, University of Florida, 700 Experiment Station Road, Lake Alfred, FL 33850, USA; Tel: (863) 956-1151; Fax: (863) 956-4631; E-mail: stelinski@ufl.edu above-described deleterious effects on pest insect physiology and behavior represents a potential alternative strategy for development of biorational controls that could replace synthetic neurotoxins. Our intent was to identify potential botanical insecticides that may prove to be effective alternatives for controlling obliquebanded leafroller.

In the current investigation, we tested the effects of several plant extracts, known to produce secondary compounds such as monoterpenes, sesquiterpenes and triterpenes [19-22] on obliquebanded leafroller larvae. These extracts were also chosen based on their previously-documented insecticidal activity $[17,18,23]$. The specific objectives of this study were to determine whether the selected plant extracts: 1) exhibit contact and/or ingestion toxicity to obliquebanded leafroller larvae, 2) affect pupal weight following ingestion by larvae, and/or 3) deter larval feeding.

\section{MATERIALS AND METHODS}

\section{Insect Culture}

Obliquebanded leafrollers were drawn from a six-yearold laboratory colony originally collected from unsprayed apple orchards in Southwestern Michigan, U.S.A. Moths were collected from the field as $1^{\text {st }}$ and $2^{\text {nd }}$ generation pupae and reared continuously without diapause. Insects were reared at $24^{\circ} \mathrm{C}$ and $60 \% \mathrm{RH}$ on a meridic pinto bean-based diet [24] under a 16:8 (L:D) photoperiod.

\section{Plant Materials}

The plant materials used in this study are given in Table 1. The detailed experimental protocol for preparing plant extracts was described by Gökçe et al. [25]. All plant materials were collected during spring and summer seasons of 2002-2005. Dried and ground plant materials were treated with methanol for $24 \mathrm{~h}$. Thereafter, the suspensions were 
Table 1. Plant Material Used to Prepare Extracts for Assaying Toxicity and Antifeedant Bioactivities against $3^{\text {rd }}$ instar Obliquebanded Leafroller Larvae. All Collections Were Made in Tokat, Turkey, 2002-2005

\begin{tabular}{|c|c|c|c|}
\hline Family Name & Scientific Name & Tissue Used & Month of Collection \\
\hline \hline Apiaceae & Bifora radians M Bieb & Leaves & April \\
\hline Asteraceae & Arctium lappa L. & Leaves & June \\
\hline Asteraceae & Xanthium strumarium L. & Fruit & August \\
\hline Canabinaceae & Humulus lupulus L. & Flower bud & September \\
\hline Scrophyllaceae & Verbascum songaricum Schrenk ex Fisch \& Mey & July \\
\hline
\end{tabular}

sieved through cheese cloth and excess methanol was removed using a rotary evaporator (RV 05 Basic 1B IKA Group, Wilmington, NC, U.S.A.) at $32 \pm 2{ }^{\circ} \mathrm{C}$. Residues of each plant species were diluted with sufficient HPLC grade acetone (Sigma-Aldrich, Milwaukee, WI, U.S.A.) to give 40 $\%(\mathrm{w} / \mathrm{w})$ stock solutions.

\section{Contact Toxicity of Plant Extracts}

This experiment tested the hypothesis that topicallyapplied plant extract solutions exhibit contact toxicity to obliquebanded leafroller larvae. Toxicity of the plant extracts was tested using $3^{\text {rd }}$ instar larvae. For each replicate, 10 larvae were transferred to a Whatman No. 1 filter paper disc in a $90 \mathrm{~mm}$ disposable Petri dish. Three replicate Petri-dishes of 10 larvae were treated with each plant extract. Each larva was treated topically with $20 \mu \mathrm{g}$ of plant extract in $1 \mu \mathrm{lof}$ acetone using a $50 \mu \mathrm{l}$ Hamilton syringe. In the control treatment, larvae were treated with $1 \mu$ of acetone. After application of treatments, the larvae were allowed to dry for $10 \mathrm{~min}$ at $25 \pm 2{ }^{\circ} \mathrm{C}$ and were subsequently transferred individually into $240 \mathrm{ml}$ soufflé cups loaded with $3.0 \mathrm{~g}$ of the meridic pinto bean diet described above. Following treatment application, larvae were maintained at $25 \pm 2{ }^{\circ} \mathrm{C}$ and on a $16: 8$ (L:D) photocycle for $48 \mathrm{~h}$, after which mortality was assessed. The experiment was repeated on three different days, which were regarded as blocks. Plant extract stock suspensions described above were prepared immediately prior to each block of assays.

\section{Toxicity of $\boldsymbol{H}$. lupulus Extract}

Additional toxicity studies were conducted using $H$. $l u$ pulus extract based on its substantial toxic effects on obliquebanded leafroller larvae in the initial screening assay (see Results). For each replicate, 10 larvae were placed on Whatman \# 1 filter paper in a $90 \mathrm{~mm}$ Petri dish. The dosages of $H$. lupulus compared were $0.3,1.5,3.0,15.0$ and $30.0 \mu \mathrm{g}$ of plant extract / insect. Insects were treated by applying $1 \mu 1$ of HPLC grade acetone solution of plant extract to the thorax using a Hamilton syringe. Control insects $(N=10 /$ replicate $)$ were treated with $1 \mu \mathrm{l}$ of HPLC grade acetone. Following application of treatments, insects were incubated as described above and mortalities were assessed after $48 \mathrm{~h}$. Each treatment was replicated three times per trial and three trials (blocks) were completed on separate days for a total of 9 Petri-dishes of 10 larvae per dose.

\section{Ingestion Toxicity and Developmental Effects of Plant Extracts}

This experiment tested the hypothesis that larval feeding on diet treated with plant extracts in a no choice context af- fects larval survival and pupal weight. Ten, 20.0 or $40.0 \mathrm{mg}$ of each plant extract in $100 \mu \mathrm{l}$ of HPLC grade acetone was incorporated per $\mathrm{g}$ of freshly prepared pinto bean diet (described above) to give 1,2 or $4 \%(w / w)$ concentrations. Each plant extract diet treatment was formulated separately. For the control treatment, $100 \mu \mathrm{l}$ of HPLC grade acetone was added to the diet. Three $g$ of each diet treatment was transferred into $240 \mathrm{ml}$ soufflé cups. To avoid cannibalism, one freshly-moulted $3^{\text {rd }}$ instar larva was transferred into each cup. The larvae were incubated at $25 \pm 2{ }^{\circ} \mathrm{C}$ and on a 16:8 (L:D) photocycle for $14 \mathrm{~d}$. Larvae were checked daily until all had pupated. Pupation was considered complete following melanization. The pupae were sexed using a dissection microscope and pupal weight was recorded using a bench balance (Sartoroius, CP124 S, Elk Grove, IL, U.S.A.). The experiment was repeated on three different days (blocks) and 30 larvae were exposed to each plant extract or control treatment per block.

\section{Feeding Deterrence Assay}

This experiment tested the hypothesis that larval feeding is deterred by plant extracts incorporated into the pinto bean diet in a choice context. Ten or $40.0 \mathrm{mg}$ of each plant extract in $100 \mu \mathrm{l}$ of HPLC grade acetone was incorporated per $\mathrm{g}$ of freshly prepared diet to give 1 or $4 \%(\mathrm{w} / \mathrm{w})$ concentrations of each extract in diet. For the control treatment, $100 \mu 1$ of HPLC grade acetone was added to the diet. For choice tests, larvae were presented with $1.0000 \pm 0.0008 \mathrm{~g}$ of diet treated with a plant extract versus an equal amount of solventtreated (control) diet in $50 \mathrm{~mm}$ round Petri dishes. Each plant extract and concentration treatment combination was tested individually versus the control. Larvae were inserted into Petri dishes individually on a piece of Whatman \# 1 filter paper $(1 \times 1 \mathrm{~cm})$ and placed centrally on portions of both treated and control diet pieces. Larvae were incubated for 72 $\mathrm{h}$ at $25 \pm 2{ }^{\circ} \mathrm{C}$ and on a 16:8 (L:D) photocycle. After incubation, the site of larval feeding was determined and scored as feeding on either extract-treated or control portions of the diet. Thereafter, larvae and visible frass were removed from diet with soft forceps and both extract-treated and control portions of the diet were weighed as described above. Remaining weights of treated and control portions of the diet were used to calculate an antifeedant index (AFI) modified from Isman et al. [26]. AFI $=(\mathrm{C}-\mathrm{T}) /(\mathrm{C}+\mathrm{T})$, where $\mathrm{C}$ and $\mathrm{T}$ are the weights of control and plant extract-treated diet consumed. Forty larvae were exposed to each plant extract or control treatment combination at both concentrations tested. Weight loss of diet due to water evaporation was quantified by establishing two positive control treatments of $1.0000 \pm$ $0.0008 \mathrm{~g}$ of diet treated with a plant extract or solvent $(N=$ 


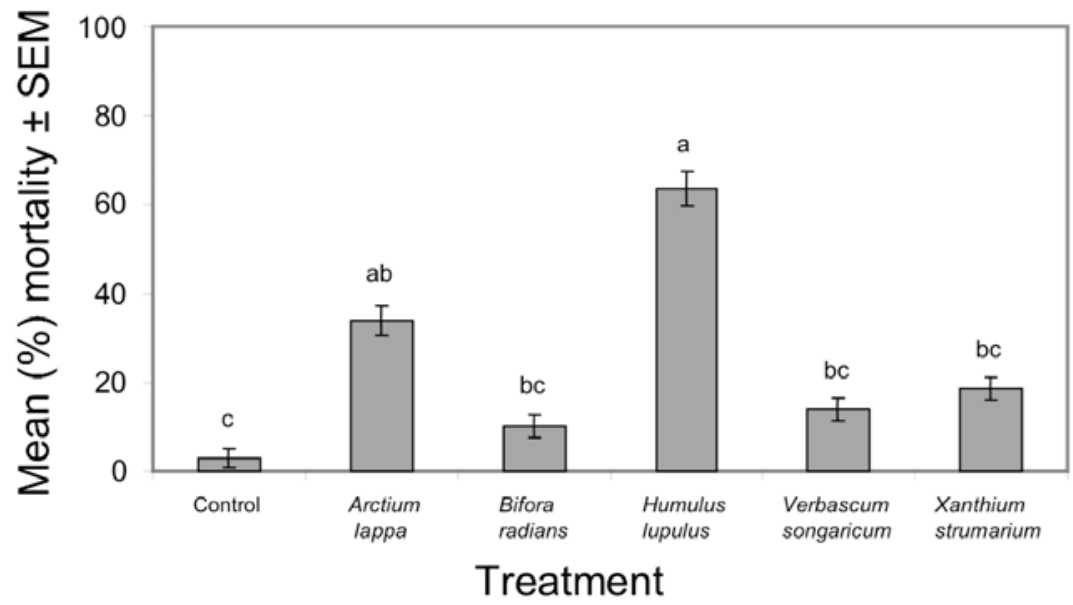

Fig. (1). Contact toxicity of selected plant-extract solutions [20 $\mu \mathrm{g}$ plant extract / insect)] to $3^{\text {rd }}$ instar obliquebanded leafroller larvae. Means indicated by different letters are significantly different $(\mathrm{P}<0.05)$ according to Tukey's test.

20). These were incubated and weighed in a manner identical to that described above.

\section{Data Analyses}

For the initial screening bioassay, data were corrected for mortality in the controls using Abbott's formula [27] and then normalized using an arcsine transformation [28]. Transformed data were submitted to a randomized complete block analysis of variance (ANOVA) $(\mathrm{P} \leq 0.05)$ and differences between treatments were compared using Tukey's test $(\mathrm{P} \leq$ 0.05). Obliquebanded leafroller larval mortality data obtained from the dose-mortality bioassay utilizing $H$. lupulus were also corrected for control mortality with Abbott's formula. The corrected mortality data were analyzed using POLO-PC [29] to estimate lethal concentration 10, 50, and 90 values $\left(\mathrm{LC}_{10}, 50\right.$, and 90) and the regression line slope. For the ingestion toxicity experiment, data were corrected with Abbott's formula and then normalized using an arcsine transformation [28]. Transformed data were submitted to a randomized complete block ANOVA $(\mathrm{P} \leq 0.05)$ and differences between treatments were tested using Tukey's test $(\mathrm{P} \leq$ 0.05). Pupal weights of male and female leafrollers were analyzed separately and submitted to a randomized complete block ANOVA $(\mathrm{P} \leq 0.05)$ followed by Tukey's test $(\mathrm{P} \leq$ $0.05)$. For the feeding choice assay, the numbers of larvae feeding on extract-treated versus control portions of the diet were compared by $\chi^{2}$ tests. All statistical analyses were carried out using MINITAB Release 14 [30].

\section{RESULTS}

\section{Contact Toxicity of Plant Extracts}

Topically-applied $H$. lupulus induced the highest mortality of obliquebanded leafroller larvae (Fig. 1). Mortality of $3^{\text {rd }}$ instar obliquebanded leafrollers was significantly $(\mathrm{F}=$ 9.8; d.f. $=5,12 ; \mathrm{P}<0.05)$ greater for larvae treated with $H$. lupulus and A. lappa plant extracts compared with the solvent control (Fig. 1). There was no significant effect $(\mathrm{P}>$ 0.05 ) of topical treatment with $B$. radians, $V$. songaricum, and $X$. strumarium extract solutions compared with the solvent control (Fig. 1).

\section{Toxicity of H. lupulus Extract}

The slope and intercepts of the dosage-mortality relationship for obliquebanded leafroller larvae treated with $H$. lupulus extract were $0.93 \pm 0.15$ and $0.02 \pm 0.02$, respectively. The $\mathrm{LC}_{10}, 50$, and 90 values (Fiducial Limits \%) were 1.03 (0.16 - 2.42), 24.52 (14.08 - 60.32), and 581.53 (164.20 to $11,724.49) \mu \mathrm{g} /$ insect, respectively.

\section{Ingestion Toxicity and Developmental Effects of Plant Extracts}

There was no significant $(\mathrm{F}=1.3 ;$ d.f $.=5,12 ; \mathrm{P}=0.32)$ effect of any of the plant extracts on survivorship of feeding larvae at the $1 \%$ concentration (Table 2). Significantly fewer $(\mathrm{F}$ 's $=7.1$ and 4.8 , d.f. $=5,12, \mathrm{P}<0.05)$ obliquebanded leafroller larvae survived to pupation at the 2 and $4 \%$ concen-

Table 2. Average Survivorship \pm S.E. of Obliquebanded Leafroller Larvae Reared on Pinto Bean Diet Containing Various Concentrations of the Plant Extracts

\begin{tabular}{|c|c|c|c|}
\hline \multirow{2}{*}{ Plant Species } & \multicolumn{2}{|c|}{ Larval Survival (\%) at Various Concentrations of Plant Extract in Diet (w/w) } \\
\cline { 2 - 4 } & $\mathbf{1 \%}$ & $\mathbf{2 ~ \%}$ & $\mathbf{4 \%}$ \\
\hline \hline Arctium lappa & $98.85 \pm 1.96 \mathrm{a}^{\mathrm{a}}$ & $90.76 \pm 4.03 \mathrm{ab}$ & $50.68 \pm 0.95 \mathrm{ab}$ \\
\hline Bifora radians & $98.85 \pm 1.96 \mathrm{a}$ & $86.98 \pm 0.38 \mathrm{~b}$ & $43.04 \pm 8.46 \mathrm{~b}$ \\
\hline Humulus lupulus & $93.10 \pm 3.19 \mathrm{a}$ & $73.50 \pm 0.25 \mathrm{~b}$ & $49.99 \pm 0.93 \mathrm{~b}$ \\
\hline Verbascum songaricum & $95.46 \pm 1.96 \mathrm{a}$ & $76.82 \pm 0.25 \mathrm{~b}$ & $67.08 \pm 3.19 \mathrm{~b}$ \\
\hline Xanthium strumarium & $100 \pm 0.00 \mathrm{a}$ & $86.98 \pm 0.38 \mathrm{~b}$ & $98.85 \pm 1.96 \mathrm{a}$ \\
\hline Solvent control & $100 \pm 0.00 \mathrm{a}$ & $100 \pm 0.00 \mathrm{a}$ & \\
\hline
\end{tabular}

${ }^{a}$ Means in a column followed by the same letter are not significantly different (ANOVA, $\left.P<0.05\right)$ followed by Tukey's mean separation $(P<0.05$ ). 
Table 3. Average Pupal Weight of Obliquebanded Leafrollers Reared on Pinto Bean Diet Containing Various Concentrations of Plant Extracts

\begin{tabular}{|c|c|c|c|c|c|c|}
\hline \multirow{3}{*}{ Plant Species } & \multicolumn{6}{|c|}{ Average Pupal Weight \pm SE (mg) at Various Concentrations of Plant Extract in Diet (w/w) } \\
\hline & \multicolumn{3}{|c|}{ Females } & \multicolumn{3}{|c|}{ Males } \\
\hline & $1 \%$ & $2 \%$ & $4 \%$ & $1 \%$ & $2 \%$ & $4 \%$ \\
\hline Arctium lappa & $85.17 \pm 2.65 \mathrm{a}^{\mathrm{a}}$ & $80.37 \pm 4.35 \mathrm{ab}$ & $61.03 \pm 5.95 \mathrm{~b}$ & $53.16 \pm 5.90 \mathrm{a}$ & $49.23 \pm 5.11 \mathrm{ab}$ & $44.93 \pm 6.75 \mathrm{~b}$ \\
\hline Bifora radians & $83.83 \pm 6.32 \mathrm{a}$ & $67.50 \pm 6.88 \mathrm{ab}$ & $47.40 \pm 8.46 \mathrm{~cd}$ & $52.93 \pm 5.66 \mathrm{a}$ & $44.73 \pm 8.37 \mathrm{ab}$ & $34.50 \pm 6.88 \mathrm{c}$ \\
\hline Humulus lupulus & $79.20 \pm 1.85 \mathrm{a}$ & $62.27 \pm 3.50 \mathrm{~b}$ & $41.80 \pm 6.68 \mathrm{~d}$ & $49.43 \pm 7.24 \mathrm{a}$ & $43.57 \pm 8.58 \mathrm{ab}$ & $30.07 \pm 6.04 \mathrm{~d}$ \\
\hline Verbascum songaricum & $79.13 \pm 1.93 \mathrm{a}$ & $56.40 \pm 2.40 \mathrm{~b}$ & $45.40 \pm 5.19 \mathrm{~cd}$ & $50.10 \pm 6.86 \mathrm{a}$ & $40.23 \pm 7.90 \mathrm{~b}$ & $31.17 \pm 5.21 \mathrm{~cd}$ \\
\hline Xanthium strumarium & $98.87 \pm 7.06 \mathrm{a}$ & $63.97 \pm 3.15 b$ & $56.40 \pm 6.40 \mathrm{bc}$ & $53.36 \pm 8.32 \mathrm{a}$ & $43.13 \pm 8.50 \mathrm{ab}$ & $36.33 \pm 5.03 \mathrm{c}$ \\
\hline Solvent control & $97.53 \pm 2.96 \mathrm{a}$ & $96.97 \pm 6.85 \mathrm{a}$ & $98.85 \pm 7.97 \mathrm{a}$ & $53.53 \pm 9.58 \mathrm{a}$ & $53.93 \pm 6.66 \mathrm{a}$ & $54.10 \pm 7.87 \mathrm{a}$ \\
\hline
\end{tabular}

${ }^{a}$ Means in a column followed by the same letter are not significantly different (ANOVA, $P<0.05$ ) followed by Tukey's mean separation $(P<0.05$ ).

trations for every plant extract treatment except A. lappa (Table 2). Larval mortality appeared to increase in a dosage dependent manner (Table 2).

Feeding by obliquebanded leafroller larvae on the diet containing $1 \%$ plant extracts (by weight) did not significantly affect pupal weight for both sexes (F's $=0.7$ and 3.1; d.f. $=5,12 ; \mathrm{P}>0.05$ for males and females, respectively) (Table 3). Increasing the concentration of plant extract in diet caused a reduction in pupal weight. Female pupal weight was significantly lower $(\mathrm{F}=5.2$; d.f. $=5,12 ; \mathrm{P}<0.05)$ for larvae feeding on the $2 \%$ concentration of $H$. lupulus, $V$. songaricum, and $X$. strumarium, while male pupal weight was significantly lower $(\mathrm{F}=4.7$; d.f. $=5,12 ; \mathrm{P}<0.05)$ only for $V$. songaricum at that concentration (Table 3). At the highest concentration tested ( $4 \%$ by weight), male and female pupal weight was significantly reduced $(\mathrm{F}=141.7$ and 75.8, respectively, d.f. $=5,12 ; \mathrm{P}<0.05$ ) for each plant extract tested (Table 3). At the $4 \%$ concentration, B. radians, $H$. lupulus, $V$. songericum, and $X$. strumarium had the greatest effect on male and female pupal weight.

\section{Feeding Deterrence Assay}

At the $1 \%$ concentration, significantly fewer $(\mathrm{P}<0.05)$ larvae were founding feeding on $B$. radians compared with the solvent control; there was no significant $(P>0.05)$ effect for the other plant extracts tested (Table 4). However, sig- nificantly fewer $(\mathrm{P}<0.05)$ larvae were found feeding on $B$. radians and $H$. lupulus -treated diet compared with the solvent control at the $4 \%$ concentration (Table 4).

At the $1 \%$ concentration, B. radians and $H$. lupulus showed evidence of feeding inhibition on the pinto bean diet with AFI's of 0.56 and 0.27 , respectively (Fig. 2A). There was a high level of feeding inhibition for $B$. radians, $H$. lupulus and A. lappa - treated diet at the $4 \%$ concentration with AFI's ranging from 0.69 to 0.85 (Fig. 2B). There was no apparent antifeedant effect of $V$. songaricum or $X$. strumarium at either concentration tested (AFI's $\approx 0$ ) (Fig. 2 A, B).

\section{DISCUSSION}

Discovery of novel toxins and/or antifeedants from plant extracts has been recently emphasized as a potential method for the development of "ecologically safe pesticides" [31]. There is ample precedent for screening crude plant extracts for biological activity as botanical insecticides against Lepidoptera. For example, crude methanolic extracts of Trichilia americana and ethanolic extracts of Annona squamosa seeds reduced pupal weight and exhibited toxic activity against the Asian armyworm, Spodoptera litura (Fabr.) [31,32]. In addition, ethanolic seed extracts of A. squamosa and A. muricata reduced larval growth of $S$. litura and the cabbage looper, Trichoplusia ni (Hbn.) [33], while acetonic seed extracts of A. squamosa showed insecticidal activity against the cabbage

Table 4. Deterrence of $3^{\text {rd }}$ Instar Obliquebanded Leafroller Larval Feeding by Plant Extracts Incorporated into Pinto Bean Diet

\begin{tabular}{|c|c|c|c|c|c|c|}
\hline \multirow{3}{*}{ Plant Species } & \multicolumn{6}{|c|}{ Proportion of Larvae Feeding on Extract-Treated Versus Control Diet } \\
\hline & \multicolumn{3}{|c|}{$1 \%$ Extract in Diet $(w / w)$} & \multicolumn{3}{|c|}{$4 \%$ Extract in Diet $(w / w)$} \\
\hline & Treatment & Control & $\chi^{2}$ & Treatment & Control & $\chi^{2}$ \\
\hline Arctium lappa & $0.45 \mathrm{a}^{\mathrm{a}}$ & $0.55 \mathrm{a}$ & 0.4 & $0.35 \mathrm{a}$ & $0.65 \mathrm{a}$ & 4.9 \\
\hline Bifora radians & $0.28 \mathrm{a}$ & $0.72 \mathrm{~b}$ & 8.1 & $0.20 \mathrm{a}$ & $0.80 \mathrm{~b}$ & 14.4 \\
\hline Humulus lupulus & $0.35 \mathrm{a}$ & $0.65 \mathrm{a}$ & 3.6 & $0.25 \mathrm{a}$ & $0.75 \mathrm{~b}$ & 10.0 \\
\hline Verbascum songaricum & $0.48 \mathrm{a}$ & $0.52 \mathrm{a}$ & 0.1 & $0.43 \mathrm{a}$ & $0.57 \mathrm{a}$ & 0.9 \\
\hline Xanthium strumarium & $0.55 \mathrm{a}$ & $0.45 \mathrm{a}$ & 0.4 & $0.42 \mathrm{a}$ & $0.58 \mathrm{a}$ & 0.4 \\
\hline
\end{tabular}

${ }^{a}$ Values in a row followed by the same letter are not significantly different $(P<0.05)$. 
head caterpillar, Crocidolomia binotalis Zeller [34]. Furthermore, crude extracts of Melia volkensii have been shown to inhibit larval growth of $T$. $n i$ and the armyworm, Pseudaletia unipunctata (Haworth) [35].

\section{(A) $1 \%$ extract in $\operatorname{diet}(\mathrm{w} / \mathrm{w})$}

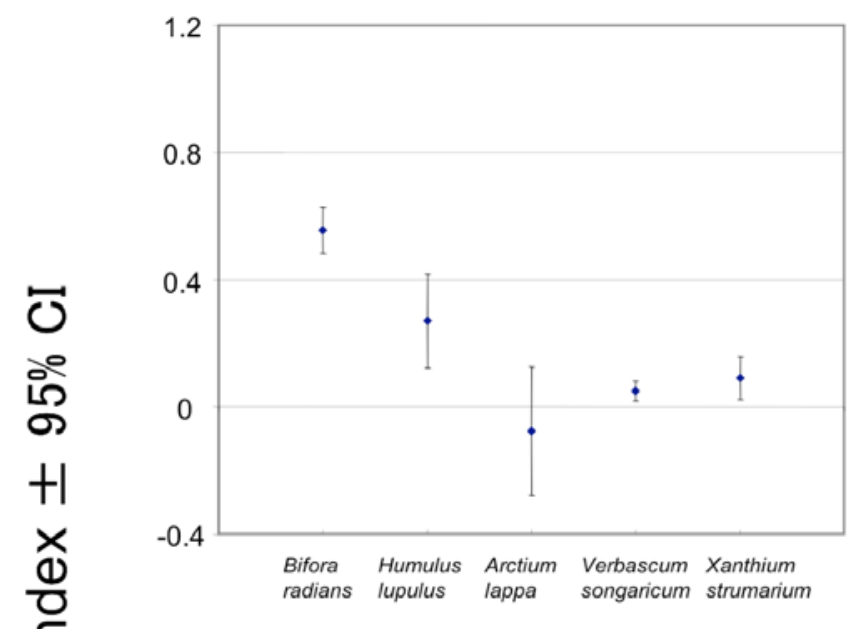

\section{(B) $4 \%$ extract in $\operatorname{diet}(\mathrm{w} / \mathrm{w})$}

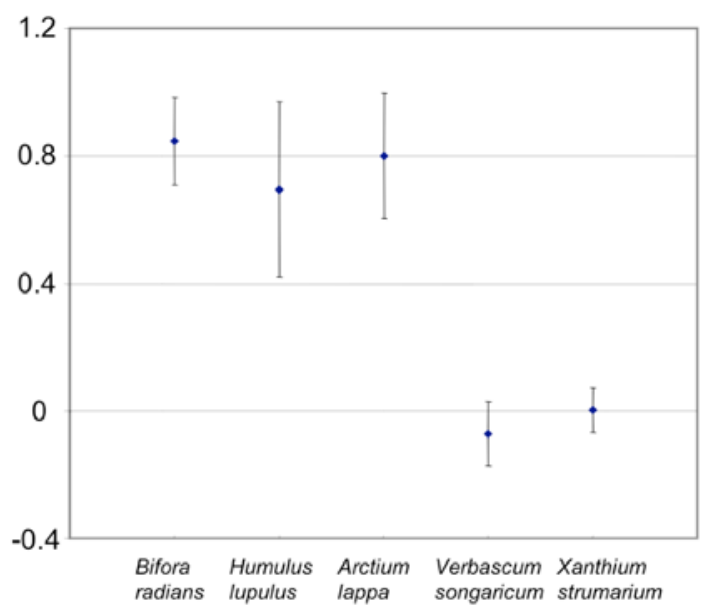

\section{Plant-extract treatment}

Fig. (2). Antifeedant effects of plant extracts incorporated into pinto bean diet at $1 \%(\mathbf{A})$ and $4 \%\left(\right.$ B) concentrations (w/w) on $3^{\text {rd }}$ instar obliquebanded leafroller larvae. AFI $=(C-T) /(C+T)$, where $C$ and $\mathrm{T}$ are the weights of control and plant extract-treated diet consumed.

Our results demonstrated that two of the plant extracts evaluated (A. lappa and $H$. lupulus) exhibited contact toxicity to obliquebanded leafroller larvae while four of the extracts decreased larval survivorship and final pupal weight following ingestion (Table 2). H. lupulus yielded the highest contact toxicity with an $\mathrm{LC}_{50}$ of $24.5 \mu \mathrm{g} /$ larva. These results are in agreement with previous studies showing pronounced contact toxicity of $H$. lupulus to various development stages of Colorado potato beetle, Leptinotarsa decemlineata (Say) $[17,18]$. The contact and ingestion toxicities induced by the tested plant extracts, particularly $H$. lupulus, suggest the potential for their future use against obliquebanded leafroller as botanical insecticides. Further testing of biological activity on other related pest species such as redbanded leafroller, Argyrotaenia velutinana (Walker), and Pandemis leafroller, Pandemis pyrusana Kearfott, is warranted.

In addition to toxicity via contact or ingestion, plant extracts and allelochemicals have been screened for activity as insect antifeedants [36-38]. In some instances, the bioactivity of crude plant extracts on insects is comprised of both toxic and antifeedant effects [32,35]. Azadirachtin, for example, derived from the neem tree (Azadirachta indica), is both a toxicant and antifeedant and has been one of the most widely tested and successfully implemented botanical insecticides over the past two decades [39-41]. In the current study, $H$. lupulus and A. lappa exhibited antifeedant activity on obliquebanded leafroller larvae in addition to contact toxicity, while $B$. radians was an antifeedant and exhibited toxic effects when ingested. $H$. lupulus, A. lappa, and B. radians are also known to deter feeding of larval $L$. decemlineata [23]. Our results suggest that potential future application of these extracts or their active components for leafroller control may exploit more than one mode of action. However, future experiments should focus on determining whether prolonged exposure of obliquebanded leafroller larvae to these plant extracts decreases antifeedant effects over time due to habituation of response [42].

H. lupulus contains alpha and beta acids, prenylflavanoids, and proanthocyanidins $[43,44]$. The beta acid derivative of $H$. lupulus repels both chewing and sucking insect pests of plants [45] and the two-spotted spider mite, Tetranychus urticae Koch [46,47]. Future studies will need to be conducted to determine whether the biological activity of $H$. lupulus against obliquebanded leafroller larvae is mediated by the beta acid component. Furthermore, identification of the bioactive components of A. lappa and B. radians may allow development of botanical insecticides with greater potency than the crude plant extracts evaluated here.

Akhtar and Isman [35] stressed the need for conducting multiple types of bioassays when screening potential botanical insecticides given that effects such as growth inhibition may not always be correlated with other consequences such as feeding deterrence. Therefore, in the current investigation, we evaluated multiple types of effects including: 1) toxicity following topical application or ingestion, 2) effects of ingestion on pupal weight, and 3) feeding deterrence. Two of the extracts tested (H. lupulus and A. lappa) induced deleterious effects for each bioassay method and thus may be the most promising candidates of those screened here for further development as botanical insecticides against obliquebanded leafroller and potentially other Lepidopteran pests. The next step toward developing these extracts as useful insecticides will focus on field testing to determine whether: 1) the toxic and antifeedant effects described here impact crop injury levels, 2) the efficacy of extracts is affected by prolonged $\mathrm{UV}$ and/or rain exposure, and 3) beneficial insects are affected.

\section{ACKNOWLEDGEMENTS}

Ayhan Gökçe was supported by TUBITAK BIDEB 2219 program during this study at Michigan State University in 
the U.S.A. We thank Krista Buehrer and Elizabeth Steere for diligent maintenance of insect colonies and diet preparation.

\section{REFERENCES}

[1] Chapman PJ, Lienk SE, Dean RW. Bionomics of Choristoneura rosaceana. Ann Entomol Soc Am 1968; 61: 285-290.

[2] Chapman PJ, Lienk SE. Tortricid fauna of apple in New York. N.Y. State Agricultural Experiment Station Geneva. Spec Publ 1971; 87-90.

[3] Weires R, Riedl H. Other tortricids on pome and stone fruits. In: van der Geest LPS, Evenhuis HH Eds, Tortricid Pests, their Biology, Natural Enemies and Control, World crop pests 5. Elsevier, Amsterdam, 1991; 412-434

[4] Waldstein DE, Reissig WH. Apple damage, pest phenology, and factors influencing the efficacy of tebufenozide for control of obliquebanded leafroller (Lepidoptera: Tortricidae). J Econ Entomol 2001; 94: 673-679.

[5] Reissig WH, Stanley BH, Hebding HE. Azinphos-methyl resistance and weight-related response of obliquebanded leafroller (Lepidoptera: Tortricidae) larvae to insecticides. J Econ Entomol 1986; 78: 692-699.

[6] Smirle MJ, Vincent C, Zurowski CL, Rancourt B. Azinphosmethyl resistance in the obliquebanded leafroller, Choristoneura rosaceana: reversion in the absence of selection and relationship to detoxification enzyme activity. Pestic Biochem Physiol 1998; 61: 183-189.

[7] Pree DJ, Whitty KJ, Pogoda MK, Bittner LA. Occurrence of resistance to insecticides in populations of the obliquebanded leafroller from orchards. Can Entomol 2001; 133: 1-11.

[8] Lawson DS, Reissig WH, Smith CM. Response of larval and adult obliquebanded leafroller (Lepidoptera: Tortricidae) to selected insecticides. J Econ Entomol 1997; 90: 1450-1457.

[9] Mochizuki A. Antifeedant activity of neem oil to rice water weevils, Lissorhoptrus oryzophilus Kuschel (Coleoptera: Curculionidae). Appl Entomol Zool 1993; 28: 254-256.

[10] Sutherland J, Baharally V, Permaul D. Use of the botanical insecticide, neem to control the small rice stinkbug Oebalus poecilus (Dallas, 1851) (Hemiptera: Pentatomidae) in Guyana. Entomotropica 2002; 17: 97-101.

[11] Duke SO. Natural pesticides from plants. In: Janick J, Simon JE Eds, Advances in New Crops. Timber Press, Portland OR, 1990; 511-517.

[12] Mordue AJ, Simmonds MSJ, Ley SV, Blaney WM, Mordue W, Nasiruddin M, Nisbet AJ. Actions of azadirachtin, a plant allelochemical, against insects. Pestic Sci 1998; 54: 277-284.

[13] Ge XS, Weston PA. Ovipositional and feeding deterrent from Chinese prickly ash against angoumois grain moth (Lepidoptera: Gelechiidae). J Econ Entomol 1995; 88: 1771-1775.

[14] Blaney WM, Simmonds MSJ, Ley SV, Jones PS. Insect antifeedants: a behavioural and electrophysiological investigation of natural and synthetically derived clerodane diterpenoids. Entomol Exp Appl 1988; 46: 267-274.

[15] Mancebo F, Hilje L, Mora GA, Salazar R. Antifeedant activity of Quassia amara (Simaroubaceae) extracts on Hypsipyla grandella (Lepidoptera: Pyralidae) larvae. Crop Prot 2000; 19: 301-305.

[16] Bruno M, Maggio AM, Piozzi F, Puech S, Rosselli S, Simmonds MSJ. Neoclerodane diterpenoids from Teucrium polium subsp. polium and their antifeedant activity. Biochem Syst Ecol 2003; 31: 1051-1056.

[17] Gökçe A, Whalon ME, Çam H, Yanar Y, Demirtaş I, Gören N. Plant extract contact toxicities to various developmental stages of Colorado potato beetles (Coleoptera: Chrysomelidae). Ann Appl Biol 2006; 149: 197-202.

[18] Gökçe A, Whalon ME, Çam H, Yanar Y, Demirtaş I, Gören N. Contact and residual toxicities of thirty plant extracts to Colorado potato beetle larvae. Arch Phytopathol Pfl 2007; 40: 441-450.

[19] Heywood VH, Harborne JR, Turner BL. The biology and chemistry of the Compositae. Academic, London, 1977.

[20] Katsiotis ST, Langezaal CR, Scheffer JJC. Composition of the essential oils from leaves of various Humulus lupulus L. cultivars. Flavour Fragrance Journal 1990; 5: 97-100.

[21] Latrasse A, Seamon E, Le Quere JL. Composition and major odorous compounds of the essential oil of Bifora radians, an aldehydeproducing weed. J High Resolut Chromatogr 1991; 14: 549-553.
[22] Baser KH, Demircakmak CB, Ermin N, Demirci F, Boyday I. The essential oil of Bifora radians Bieb. J Essen Oil Res 1998; 10: 451452.

[23] Gökçe A, Isaacs R, Whalon ME. Behavioural response of Colorado potato beetle (Leptinotarsa decemlineata) larvae to selected plant extracts. Pest Manag Sci 2006; 62: 1052-1057.

[24] Shorey HH, Hale RL. Mass-rearing of the larvae of nine noctuid species on a simple artificial medium. J Econ Entomol 1965; 58: $522-524$.

[25] Gökçe A, Stelinski LL, Whalon ME. Behavioral and electrophysiological responses of leafroller moths to selected plant extracts. Environ Entomol 2005; 34: 1426-1432.

[26] Isman MB, Koul O, Luczynski A, Kaminski A. Insecticidal and antifeedant bioactivities of neem oils and their relationship to azadirachtin content. J Agric Food Chem 1990; 38: 1406-1411.

[27] Abbott WS. A method for computing the effectiveness of an insecticide. J Econ Entomol 1925; 18: 265-267.

[28] Zar JH. Biostatistical analysis. Prentice-Hall Inc, Upper Saddle River, NJ, USA, 1999

[29] LeOra Software. Polo-PC: probit and logit analysis. LeOra Software, Berkeley, CA, USA, 1994.

[30] McKenzie JD, Goldman R. The student guide to Minitab release 14 manual. Pearson Education Inc, Boston, MA, USA, 2005

[31] Wheeler DA, Isman MB, Sanchez-Vindas PE, Arnason JT. Screening of Costa Rican Trichilia species for biological activity against the larvae of Spodoptera litura (Lepidoptera: Noctuidae). Biochem Syst Ecol 2001; 29: 347-358.

[32] Wheeler DA. Isman MB. Antifeedant and toxic activity of Trichilia americana extract against the larvae of Spodoptera litura. Entomol Exp Appl 2001; 98: 9-16.

[33] Leatemia JA, Isman MB. Insecticidal activity of crude seed extracts of Annona spp., Lansium domesticum and Sandoricum koetjape against Lepidopteran larvae. Phytoparasitica 2004; 32: 30-37.

[34] Prijono D, Gani MS, Syahputra E. Insecticidal activity of annonaceous seed extracts against Crocidolomia binotalis Zeller (Lepidoptera: Pyralidae). Bull Plant Pest Dis 1997; 9: 1-6.

[35] Akhtar Y, Isman MB. Comparative growth inhibitory and antifeedant effects of plant extracts and pure allelochemicals on four phytophagous insect species. J Appl Entomol 2004; 128: 3238.

[36] Koul O, Isman MB. Toxicity of the allelochemical cedrelone to noctuid larvae. Entomol Exp Appl 1992; 64: 281-287.

[37] Koul O. Plant allelochemicals and insect control: an antifeedant approach. In: Ananthakrishnan TN, Raman A Eds, Chemical Ecology of Phytophagous Insects. Oxford and IBH, New Delhi, 1993; 51-80.

[38] Chen W, Isman MB, Chiu SF. Antifeedant and growth inhibitory effects of the limonoid toosendanin and Melia toosendan extracts on the variegated cutworm, Peridroma saucia. J Appl Entomol 1995; 119: 367-370.

[39] Schmutterer H. Properties and Potential of Natural Pesticides from the Neem Tree, Azadirachta indica. Annu Rev Entomol 1990; 35: 271-297.

[40] Schmutterer H. Higher plants as sources of novel pesticides. In: Otto D, Weber B Eds, Andover Insecticides: Mechanisms of Action and Resistance. Intercept Ltd, 1992; 3-15.

[41] Schmutterer $\mathrm{H}$. The neem tree-a source of unique products for pest management and other purposes. $\mathrm{VCH}$, Weinheim, 1995.

[42] Bomford MK, Isman MB. Desensitization of fifth instar Spodoptera litura to azadirachtin and neem. Entomol Exp Appl 1996; 81: 307-313.

[43] Hoek AC, Hermans-Lokkerbol ACJ, Verpoorte R. An improved NMR method for the quantification of $\alpha$-acids in hops and hop products. Phytochem Anal 2001; 12: 53-57.

[44] Taylor AW, Borofsky E, Kennedy JA, Deinzer ML. Hop (Humulus lupulus L.) proanthocyanidins characterized by mass spectrometry, acid catalysts, and gel permeation chromatography. J Agric Food Chem 2003; 51: 4101-4110.

[45] Hampton R, Nickerson G, Whitney P, Haunold A. Comparative chemical attributes of native North American hop, Humulus lupulus var. lupuloides E. Small. Phytochemistry 2002; 61: 855-862.

[46] Jones G, Campbell CAM, Pye BJ, Maniar SP, Mudd. A. Repellent and oviposition-deterring effects of hop beta-acids on the twospotted spider mite Tetranychus urticae. Pestic Sci 1996; 47: 165169. 
[47] Jones G, Campbell CAM, Hardie J, Pickett JA, Pye BJ, Wadhams LJ. Integrated management of two-spotted spider mite Tetranychus urticae on hops using hop beta-acids as an antifeedant together with the predatory mite Phytoseiulus persimilis. Biocontrol Sci Techn 2003; 13: 241-252.

(C) Gökçe et al.; Licensee Bentham Open.

This is an open access article licensed under the terms of the Creative Commons Attribution Non-Commercial License (http://creativecommons.org/licenses/by-nc/3.0/) which permits unrestricted, non-commercial use, distribution and reproduction in any medium, provided the work is properly cited. 